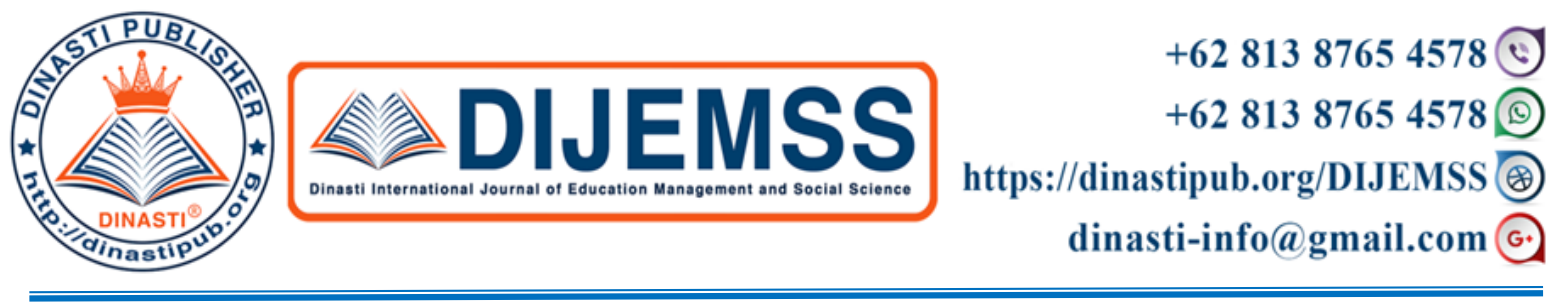

\title{
MEDIA RICHNESS ON INSTAGRAM INFLUENCES TOWARDS CONSUMER PURCHASE INTENTION: EXPLORING THE MODERATING EFFECT OF BRAND EQUITY
}

\author{
Muhammad Asyraf Hasim ${ }^{1)}$, Mohd Fikri Ishak ${ }^{2)}$, Nurul Nadia Abdul Halim ${ }^{3)}$, Arman \\ Hj Ahmad ${ }^{4)}$, Putu Ngurah Suyatna ${ }^{5}$ \\ 1, 2,3,4)Universiti Kuala Lumpur Business School, Malaysia \\ ${ }^{5)}$ Universitas Warmadewa, Indonesia
}

\begin{tabular}{|c|c|}
\hline $\begin{array}{r}\text { Correspondine } \\
\text { First Aut } \\
\text { E-mail } \\
\text { asyrafhasim@uni } \\
\text { ifikrie81@gm } \\
\text { nadia.halim22@s.u } \\
\text { arman@unikl. } \\
\text { putungurahsuyatna }\end{array}$ & $\begin{array}{l}\text { Abstract: Social media has become a widely-adopted } \\
\text { technology since it being introduced to the world, affecting } \\
\text { businesses in myriad ways. Majority of companies nowadays } \\
\text { started to invest on social media marketing in regards to the } \\
\text { ability of this marketing initiative lead to better profitability. } \\
\text { However, only few studies have looked at the empirical link } \\
\text { between media richness from social media i.e. Instagram and } \\
\text { purchase intention among consumers. This paper discusses the } \\
\text { influences of media richness on Instagram towards consumers' } \\
\text { intention to purchase mediated by brand equity. This study was } \\
\text { conducted utilising survey research method, aiming to create } \\
\text { better understanding of consumer intention to purchase as being } \\
\text { influenced by social media richness. A total of } 537 \\
\text { undergraduate students in Kuala Lumpur, Malaysia age } 19 \text { to } 24 \\
\text { years old took part in this study as respondents. The respondents } \\
\text { are exposed to Instagram postings on similar products for sale. } \\
\text { Partial least square structural equation modelling (PLS-SEM) } \\
\text { applied to fit the data in the hypothesised model. The outcome } \\
\text { of study is useful to both researchers and business practitioners } \\
\text { to understand the importance of social media richness } \\
\text { specifically utilising Instagram as business platform. Future } \\
\text { study should consider on discovering different perspective of } \\
\text { media richness involving other types of social media. } \\
\text { Keywords: Social Media, Instagram, Purchase Intention, } \\
\text { Media Richness Theory, Brand Equity }\end{array}$ \\
\hline
\end{tabular}

\section{INTRODUCTION}

The pervasive of social media today is because of its availability to consumers for free as well as its function to enable people to connect and communicate each other. What makes social media is so interesting and not the same as traditional media is that the advertisers may 
now be able to interact with customers in real-time; making social media today the best platform for customer engagement activity. There are number of studies by scholars on social media richness effective identifying purchase intention influence. However, there is still a need to further research this new marketing trend. This study focus in giving better overview on methods to measure the potential return on investment in social media marketing technique through selected variables.

This study refers to media richness theory proposed by Daft, Lengel, and Trevino (1987) which suggested that the degree of information dissemination can enhance a receiver's degree of comprehension. Based on this theory, if media richness is high, meaning that information dissemination is better, and if media richness is low, meaning that the equivocality and uncertainty in the process of information dissemination are high. In addition, face-to-face communication is the richest communication medium in the hierarchy followed in order by video, voice and text. The theory also suggests the effective use of a communication channel (medium) by matching the richness of a medium and the equivocality of task. Sets of questionnaires of this study distributed conveniently to 537 undergraduate students at several private universities in Kuala Lumpur, Malaysia to measure the media richness effect towards brand equity and purchase intention in the case of Instagram platform.

\section{LITERATURE REVIEW \\ Social Media Richness}

Daft et al. (1987) proposed and agreed on media richness theory on the degree of information dissemination by media can enhance a receiver's degree of understanding. This theory highlighted that different media hold different information richness. The higher media richness of medium used, the better dissemination of information. The lower media richness of medium used, the poorer dissemination of information, which this is due to high uncertainty and equivocality in the process of information being distribute to the receiver. Daft et al. (1987) formed a hierarchy consists of (i) instant feedback availability; (ii) ability of the medium to transmit multiple signals; (iii) use of natural language; and (iv) the personal focus on the medium. Based on the hierarchy, the richest communication medium is face-to-face, followed by video, voice, and text. Brunell (2009) believed that consumers desire a communication medium offering relevant information as highlighted in media richness theory. However, the information must be accurate, timely, interesting, and understandable by consumers so that they have the intention to buy (Aydogan, Aktan, \& Aysuna, 2016).

Apart of offering information via communication medium, Teo, Leng, and Pua (2019) in their study prove that image quality also give significant impact to purchase intention among consumers. For online business perspective, the best approach in developing electronic commerce strategy is to enrich company-consumer interface. Tseng, Cheng, Li, and Teng (2016) in their study on Mobile Instant Messaging shows that media richness (multiple cues, immediate feedback, personal focus, and language variety) increases consumer loyalty. Based on previous studies, interesting and good media richness theory elements implementation on a communication medium, lead to purchase intention and loyalty. Specific to social media platform, Instagram in this case, eye-catching visuals and excellent engaging option available on this platform expected to have positive relationship with purchase intention among consumers. According to Valentini, Romenti, Murtarelli, and Pizzeria (2018), presenting 
images is a more direct way of communication, better experience in human relations as compared to text-based communication.

\section{Instagram}

Instagram is a free mobile photo-sharing application. It allows users to snap and edit photos instantly and then share the photos to private photo-sharing community or to the public which completely to be viewed by strangers who wish to do so on the Instagram account. Photos and videos posted on Instagram can also be viewed across various social media platforms such as Facebook and Twitter as long as the account owner allow it. Instagram defines itself as "a free photo and video sharing app available on Apple iOS, Android and Windows Phone where people can upload photos or videos and share them with their followers or with a select group of friends. They can also view, comment and like posts shared by their friends on Instagram" ("What Is Instagram?", 2019). Instagram had approximately one billion monthly active users worldwide, and more than 500 million of them use the platform everyday who had shared more than 30 billion phots (Clarke, 2019). While the industry has extensively embraced this social media platform, the academic studies on Instagram lags far behind. In academic literatures, only a limited number of studies have been conducted to specifically examine Instagram usage and marketing.

\section{Brand Equity}

Brand equity is one of the most crucial elements in the field of brand management and marketing from both academic and managerial perspectives (Yang, Liu, \& Li, 2015). Early studies identified brand equity as "a set of brand assets and liabilities linked to a brand, its name, and symbol, that add to or subtract from the value provided by a product or service to a firm and/or to that firm's customers" (Aaker, 1991). The author highlighted on four components of brand equity i.e. brand awareness, perceived quality, brand associations, and brand loyalty. Other study in brand equity by Keller (1993) emphasised on the brand equity as "the differential effect that brand knowledge has on consumer response to the marketing of that brand" by categorised into two which are brand awareness and brand image. Brand awareness is the extent to consumer's ability to recognise or recall a brand separately from other brands under different conditions while brand image refers to the consumer perception of the brand. In this particular study, the research has chosen brand equity model developed by Aaker (1991) and focusing on consumer perspective.

However, recent studies concluded that brand equity as a relational market-based asset generated by means of interactions and relationships between brands and consumers (e.g., Davcik, Vinhas da Silva, \& Hair, 2015; Hooley, Greenley, Cadogan, \& Fahy, 2005; Srivastava, Fahey, \& Christensen, 2001). Brand equity also create strong emotion connection between the brand and the consumers which influences the consumer to think about the brand the next time the consumer wants to make a purchase (Forbes, 2017). A part from that, brand equity is value added by the brand name that causes long term profit for a business organisation (Cousaris, Osch, \& Balogh, 2016). The value of focusing on brand equity by organisations have been subject to extensive debate, just as the discussion of what encompasses brand equity and how it can be built with diverse business decision (Christodoulides \& De Chernatony, 2010). Regardless of different arguments and opinions regarding their relative importance and 
measurement, most scholars agree that stronger brand equity contributes to increased brand preference, willingness to pay a premium price, and created loyal customers (Aaker, 1991; Keller, 2003; Keller \& Lehmann, 2006). Kim and Ko (2012) reveal that in social media settings brand equity that social media marketing activities create is positively related to consumer purchase behaviour. This study therefore focuses on the influence of social media richness, brand equity, and consumer purchase intention.

\section{Purchase Intention}

Purchase intention is a consumer behaviour that inclined towards future purchase planning (Dodds, Monroe, \& Grewal, 1991). In other words, it is a consumer's possibility of purchasing in the future. Since purchase intention convey a customer's will to promise certain activity related to future doing, countless studies have been employed to estimate the factors that can give influence to this phenomenon. Therefore, understanding consumers' purchasing behaviour i.e. purchase intention is necessary to business organisation in order to attract and retain customers (Ko, Kim, \& Zhang, 2008). Previous researches showed that purchase intention is strongly related to attitude, environment, situation, and preference towards a brand or a product (Kim \& Ko, 2012; Kumar, Kim \& Lee, 2009). Ayuningthyas, Prihatiningsih, \& Laura (2018) in their recent study found a positive relationship between products availability on social media and purchase intention.

Today, social media is a must have marketing tool for any business organisation as it has significant impact on customer intention to purchase. Different with traditional shop, an online shop may have small human contact on the purchase process. Therefore, online shop depends on the media richness to engage and encourage customer to purchase. Brunell (2009) in his empirical study has developed a framework to explain consumer purchase intention when they shop online and he found that consumer will decide to purchase a product if the social media platform offer the information they desired. Therefore, based on the above discussions on three constructs namely Social Media Richness, Brand Equity, and Purchase Intention, this study had come out with the following hypotheses that sums up the research objectives:

Hypothesis 1: Social Media Richness has direct effect on Purchase Intention Hypothesis 2: Brand Equity moderates the relationship between Social Media Richness and Purchase Intention

\section{METHODOLOGY}

This study applying quantitative method and the respondent comprised of Generation $\mathrm{Z}$ (Gen Z) in Kuala Lumpur, Malaysia. Gen Z had been defined as people who were born from 1995 to 2010 (Francis \& Hoefel, 2018), by means they are now age 19 years old to 24 years old at the moment this study has been conducted. They are exposed to digital online application from the earliest youth as they were connected to internet mobile systems (Francis \& Hoefel, 2018). In fact, this generation are the most active social media mobile apps user as compared to other generations (Green, 2019). A set of 600 questionnaires were distributed conveniently to undergraduate students among various private universities in Kuala Lumpur, Malaysia. However, only 537 completed return questionnaires are valid for this study. 
The respondents are grouped in a closed hall where they were exposed to a similar brands and products on Instagram online business posts from their own smart phones. The number of "likes" from each Instagram posts were hidden from the respondents to avoid bias. The respondents were then asked to answer questionnaires provided regarding their response towards social media richness and purchase intention by Instagram posts they experienced in the closed hall. Several respondents' demographic profiles were gathered. Table 1 presents the demographic details of the study respondents.

Table 1: Respondents Demographic Profile

\begin{tabular}{lllc}
\hline \multicolumn{1}{c}{ Variable } & Categories & N & Percentage (\%) \\
\hline Gender & Male & 248 & 46.2 \\
& Female & 289 & 53.8 \\
Age & $19-24$ & 537 & 100.0 \\
Monthly Income & Below 1,000 MYR & 537 & 100.0 \\
Online Shopping Experience via & Yes & 537 & 100.0 \\
Social Media & & & \\
Education & Bachelor Degree & 537 & 100.0 \\
\hline
\end{tabular}

\section{Data Analysis}

This study utilised SmartPLS 3 software as research analysis tool to explore on the moderating effect of brand equity on the relationship between Social Media Richness and Consumer Purchase Intention. As per Partial Least Square (PLS) - Structural Equation Modelling requirements, there are two main assessments are required which are measurement model and structural model (Hair et al., 2017; Anderson \& Gerbing, 1988).

\section{Measurement model assessment summary:}

The main purpose of measurement model assessment is test the reliability and validity of the items in the constructs. All constructs which are Social Media Richness (SMR), Brand Equity (BE) and Purchase Intention (PI) were developed based on reflective model. Hair et al., (2017) highlighted that there are three main steps required in assessing the measurement model which is Internal Consistency, Convergent Validity and Discriminant validity. Based on PLSAlgorithm, the results show that the Composite Reliability (CR) for all construct above 0.9 and Cronbach Alpha above 0.9. While the Convergent Validity results shows that the Indicator reliability above 0.7 and the AVE's were above 0.5 . Table 2 summarizes the PLS outcome of the outer model. 
Table 2: Summary of Measurement Model Results

\begin{tabular}{lcccc}
\hline & $\begin{array}{c}\text { Cronbach's } \\
\text { Alpha }\end{array}$ & rho_A & $\begin{array}{c}\text { Composite } \\
\text { Reliability }\end{array}$ & $\begin{array}{c}\text { Average } \\
\text { Variance } \\
\text { Extracted } \\
\text { (AVE) }\end{array}$ \\
\hline Brand Equity (BE) & 0.922 & 0.926 & 0.933 & 0.520 \\
\hline Purchase Intention (PI) & 0.930 & 0.931 & 0.956 & 0.878 \\
\hline Social Media Richness (SMR) & 0.910 & 0.923 & 0.924 & 0.551 \\
\hline
\end{tabular}

Besides that, the Discriminant Validity result of Fornell Larker's criterion had shown that each constructs were distinct and met the discriminant validity test. Each of the square root of AVEs for each Latent Variable (LV) was greater than the correlation among the LVs. Moreover, Cross Loading result also showed that the outer loading value was greater than its loading with all other remaining constructs. Table 3 shows the discriminant validity analysis of Fornell \& Larcker's criterion.

Table 3: Fornell and Larcker's Table

\begin{tabular}{lrrr}
\hline & $\begin{array}{c}\text { Brand Equity } \\
(\mathrm{BE})\end{array}$ & $\begin{array}{c}\text { Purchase } \\
\text { Intention (PI) }\end{array}$ & $\begin{array}{c}\text { Social Media } \\
\text { Richness (SMR) }\end{array}$ \\
\hline Brand Equity (BE) & $\mathbf{0 . 6 4 1}$ & & \\
Purchase Intention (PI) & 0.725 & $\mathbf{0 . 8 6 0}$ & $\mathbf{0 . 7 2 1}$ \\
\hline Social Media Richness (SMR) & 0.611 & 0.632 & \\
\hline
\end{tabular}

The abovementioned on the measurement model result had assured that this study had adopted a valid and reliable measurement for all the items and constructs. Henceforth, the result had indicated the measurement model was fit for further structural assessment in predicting the relationship strength and hypotheses testing and validation. The second stage of structural model assessment on the causal relationship between the latent constructs that underline the theoretical relationships was conducted that focus on indices produced by PLS-SEM analysis such as path coefficient for the relationship strength as well as bootstrapping routine output was referred in determining its significant, the coefficient of determinant $\left(\mathrm{R}^{2}\right)$ as well as the effect size (f2) (Hair et al., 2017).

\section{Structural model assessment summary:}

As for the structural model assessments, the path coefficient of all causal related latent variable are to be identified through PLS-SEM analysis. The path coefficient of $\beta$ values are to be assessed between value of -1 to 1 that reflects its strength (Cohen, 1988). The analysis outcome for structural model had explicated a positive significance relationship between SMR (social media richness) and PI (purchase intention) indicated by path coefficient of $\beta 0.337$; $t$ value of 4.131 and $p$-value of 0.000 (Hair et al, 2017). 
Furthermore, on interaction (moderation) effect of BE (brand equity) on the relationship path between SMR and PI were analysed using orthogonalization approach with standardised product term calculation (Hair, Hult, Ringle, \& Sarstedt, 2017). This approach has been selected due to its ability to increase the interpretability of the overall result of the moderator analysis. In other words, this approach will greatly facilitate the interpretation of the moderating effect's strength which in-line with this study objective. Plus, this approach was preferred due to its performance in minimising estimation bias (Henseler \& Chin, 2010).

The outcome of PLS-SEM run had indicated that there was an interaction (moderation) effect explained by path coefficient of $\beta$ value of 0.271 . However, requirement for further testing was conducted by utilising bootstrapping routine in determining the significance level of the path relationship and influence had suggested similarly. The result showed that $p$-value of 0.000 and $t$-value of 2.449. Henceforth, the result of interaction (moderation) assessment had clearly shown that the BE (brand equity) interacted as a significant moderator on relationship path between SMR and PI indicated by matched $t$ and $p$ values of two-tailed test (p-value < 0.05 and t-value >1.96). Thus, analyses on structural model had confirmed that hypotheses of $\mathrm{H} 1$ and $\mathrm{H} 2$ were accepted.

Table 4: Hypothesis Test for Structural Model

\begin{tabular}{llcccc}
\hline Hypothesis & $\begin{array}{c}\text { Path } \\
\text { Coefficient }\end{array}$ & $\begin{array}{c}\text { T- } \\
\text { Value } \\
(>\mathbf{1 . 9 6})\end{array}$ & $\begin{array}{c}\text { P- } \\
\text { Value } \\
(<\mathbf{0 . 0 5})\end{array}$ & $\begin{array}{c}\text { Supported } \\
(\text { Yes/No) }\end{array}$ \\
\hline $\mathrm{H}_{1}$ & $\begin{array}{l}\text { Social Media Richness (SMR) } \rightarrow \\
\text { Purchase Intention (PI) }\end{array}$ & 0.444 & 7.209 & 0.000 & Yes \\
\hline $\mathrm{H}_{2}$ & Brand Equity (BE) (moderation) & 0.271 & 2.449 & 0.000 & Yes \\
\hline
\end{tabular}

Apart from that, the main effect assessments of the overall structural data were carried out by determining the model's predictive power between certain endogenous construct that are linked with exogenous construct(s) are to be assessed by looking at the coefficient of determinant of $\mathrm{R}^{2}$. The result of the is $\mathrm{R}^{2}$ was 0.327 indicated that Social Media Richness and Brand Equity explained $32.7 \%$ of the variance in Purchase Intention. Interaction effect model (with moderator) result is 0.341 which is $34.1 \%$. The $\mathrm{R}^{2}$ change of 0.014 indicates that with the addition of one interaction term, the $\mathrm{R}^{2}$ has changed about $1.4 \%$ (additional variance).

Calculation of effect size $\left(f^{2}\right)$ is using the formula $f^{2}=\mathrm{R}^{2}$ with moderator $-\mathrm{R}^{2}$ without moderator $/ 1-\mathrm{R}^{2}$ with moderator which translated into $f^{2}=0.341-0.327 / 1-0.341=0.0212$. Cohen (1988) proposed that interpretation of $f^{2}$ values of $0.02,0.15$, and 0.35 represent small, medium, and large effect size. Based on $f^{2}$ of 0.0212 this study conclude that the effect size is small (Cohen, 1988). Low effect size of $f^{2}$ does not necessarily imply that the underlying moderator effect is not important. Figure 1 shows the structural model of this study. 


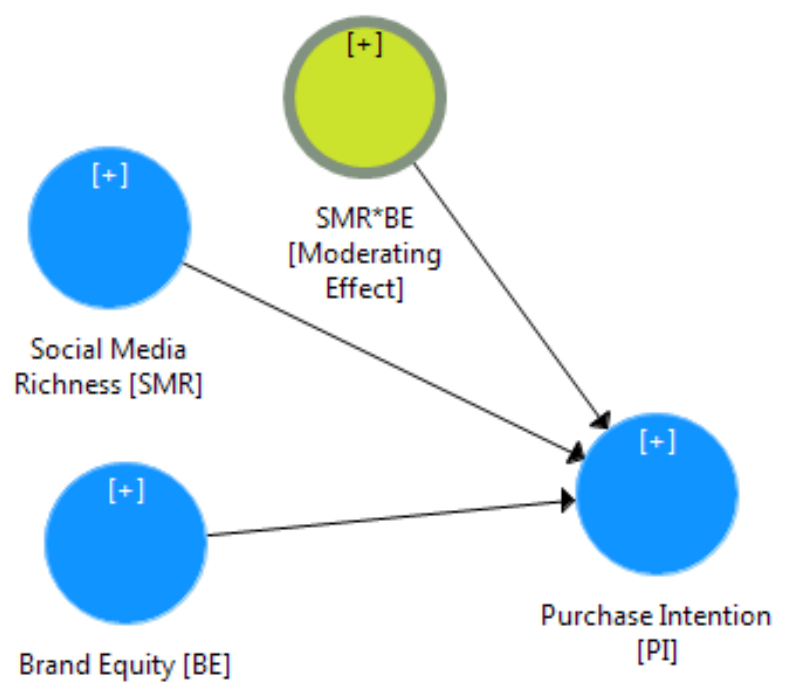

Figure 1: PLS-SEM Structural Model

\section{DISCUSSION}

This study has found significant direct relationships between social media richness purchase intention. Other than that, this study also concluded that there was a significant relationship of interaction (moderating) effect of $\mathrm{BE}$ (brand equity) on path relationship between social media richness and purchased intention. Evidently, the interaction effect found in this study was based statistical explanation denoted by path coefficient of $\beta$ value of 0.271 with significant $t$ and $p$ values. Social media richness has a medium explanatory power to predict purchase intention which explained $32.7 \%$ of the variance. Consequently, this study found that social media richness was a significant variable that influence intention to purchase.

Moreover, positive relationship exists between social media richness towards purchase intention explicates positive influence on consumer by having social media richness on Instagram (in terms of attractiveness, contents, and user interface), thus, induces intention to purchase. This behaviour also eventuate when consumers are triggered by interesting approach provides by social media platform (i.e. Instagram) in promoting the product online which lead to purchase intention. Therefore, when the consumers being nourished by social media richness on Instagram, there is high possibility to resist from looking to other social media applications promoting the same products or services. On that account, marketers should focus on social media richness as it plays a vibrant role in impelling purchase intention among consumers. This study shows that the richness of the contents can influence consumer intention to purchase.

\section{CONCLUSIONS AND FUTURE RESEARCH}

Positive relationship exists between social media richness towards purchase intention means that consumers have the intention to purchase if they were provided with decent media richness from the social media platform (i.e. in this case Instagram). Specific to this study, attractiveness, media contents, and user interface becoming the indicator to measure the media richness offered. Brand equity was found to have a significant interaction between social media richness and purchase intention. Therefore, the existing of brand equity as moderator had played 
a significant interactor in the relationship between social media richness and purchase intention. Based on theoretical and empirical suggestion, hypotheses developed for this study was accepted based on empirical data gathered within this context verified through statistical justifications].

To conclude, Gen- $Z$ in Kuala Lumpur, Malaysia are sensitive and thoughtful about social media richness by the online sellers on Instagram in order for them to have the intention to purchase and brand equity did contribute as a positive significant interactor that influences customer's buying intention. Indeed, the findings of this study is limited to Malaysia setting as it was conducted only in the capital city of Malaysia. Plus, the scope of research only focusing on Gen-Z among undergraduate students. There may be differences in terms of findings if this study being tested at different nations and respondent's group. Future studies may consider using a national sample which is more accurate reflects the population of current and potential online consumers. The influence of social media richness in terms of attractiveness, media contents, and user interface, and brand equity towards purchase intention may vary between Gen-Z and other generations such as Generation X and Generation Y. Other than that, future study should also consider on discovering other variables, applying different social media platforms, as well as different product brands.

\section{REFERENCES}

Aaker, D. A. (1991). Managing brand equity: Capitalizing On the Value of a Brand Name. New York, NY: Free Press

Anderson, J. C., \& Gerbing, D. W. (1988). Structural equation modeling in practice: A review and recommended two-step approach. Psychological Bulletin, 103(3), 411-423. https://doi.org/10.1037/0033-2909.103.3.411

Aydogan, S., Aktan, M., Universitesi, M., \& Aysuna, C., (2016) Web Advertising Value and Students' Attitude Towards Web Advertising, European Journal of Business and Management, Vol 8(9)

Ayuningtyas, F., Prihatiningsih, W., \& Laura, R. (2018). The Pattern of Online Purchase Behavior by Millennial Family. Malaysian Journal of Social Sciences and Humanities (MJSSH), 3(5), 10 - 16.

Brunell, E., (2009) Introducing Media Richness into Integrated Model of Consumers' Intentions to Use Online Stores in Their Purchase Process, Journal of Internet Commerce, 8, pp 222-245

Christodoulides, G., \& De Chernatony, L. (2010). Consumer-based Brand Equity Conceptualization and Measurement - A literature review. International Journal of Market Research, 52(1), 43-66.

Cohen, J. (1988). Statistical Power Analysis for the Behavioural Science (2 ${ }^{\text {nd }}$ Ed.). Hillsdale, NJ: Lawrence Erlbaum Associates.

Cousaris, C.K., Osch, W.V., \& Balogh, B.A., (2016) Do Facebook Like Lead to Share or Sales? Exploring The Empirical Links Between Social Media Content, Brand Equity, Purchase Intention, and Engagement, $49^{\text {th }}$ Hawaii International Conference on System Science, pp $3456-3555$

Clarke, Todd (2019). 22+ Instagram Stats That Marketers Can't Ignore This Year. Accessed September 21, 2019 from https://blog.hootsuite.com/instagram-statistics/ 
Daft, R. L., Lengel, R. H., \& Trevino, L. K. (1987). Message Equivocality, Media Selection, and Manager Performance: Implications for Information Systems. MIS Quarterly, 11(3), $355 \mathrm{e} 366$

Davcik, N. S., Vinhas da Silva, R., \& Hair, J. F. (2015). Towards A Unified Theory of Brand Equity: Conceptualizations, Taxonomy and Avenues for Future Research. The Journal of Product and Brand Management, 24(1), 3-17

Dodds, W.D., Monroe, K.B., \& Grewal, D., (1991) Effect of Price, Brand, and Store Information on Buyers' Product Evaluation. Journal of Marketing Research, pp. 307-319

Forbes (2017). Building Brand Equity. Accessed September 21, 2019 from https://www.forbes.com/sites/propointgraphics/2017/07/08/building-brandequity/\#75258db56e8f

Francis, Tracy \& Hoefel, Fernanda (2018). ‘True Gen': Generation Z and Its Implications For $\begin{array}{lllll}\text { Companies. } & \text { Accessed } & \text { September } & 2019 & \text { from }\end{array}$ https://www.mckinsey.com/industries/consumer-packaged-goods/our-insights/true-gengeneration-z-and-its-implications-for-companies

Green, Dennis (2019). Business Insider. The Most Popular Social Media Platforms with Gen-

Z. Accessed August 17, 2019 from https://www.businessinsider.my/gen-z-lovessnapchat-instagram-and-youtube-social-media-2019-6/

Hair, J.F., Hult, G.M., Ringle, C.M., and Sarstedlt, M. (2017). A Primer on Partial Least Squares Structural Modelling (PLS-SEM). USA: Sage Publication, Inc.

Henseler, J., \& Chin, W. W. (2010). A Comparison of Approaches for the Analysis of Interaction Effects between Latent Variables using Partial Least Squares Path Modelling. Structural Equation Modelling, 17(1), 82-109

Hooley, G. J., Greenley, G. E., Cadogan, J. W., \& Fahy, J. (2005). The Performance Impact of Marketing Resources. Journal of Business Research, 58(1), 18-27

Keller, K. (1993). Conceptualizing, Measuring, and Managing Customer-Based Brand Equity. Journal of Marketing, 57(1), 1-22.

Keller, K. (2003). Understanding brands, branding and brand equity. Journal of Direct, Data and Digital Marketing Practice, 5, 7-20.

Keller, K. L., \& Lehmann, D. R. (2006). Brands and branding: Research findings and future priorities. Marketing Science, 25(6), 740-759.

Kim, A.J. and Ko, E. (2010). The Impact of Design Characteristics On Brand Attitude And

Purchase Intention: Focus On Luxury Fashion Brands. Journal of the Korean Society of Clothing and Textiles, 34(2), 252-265.

Kim, A. J., \& Ko, E. (2012). Do Social Media Marketing Activities Enhance Customer Equity? An Empirical Study of Luxury Fashion Brand. Journal of Business Research, 65, 14801486.

Ko, E., Kim, K.H., and Zhang, H. (2008). A Cross Cultural Study of Antecedents of Purchase Intention for Sports Shoes in Korea and China. Journal of Global Academy of Marketing Science, 18(1), 157-177

Kumar, A., Lee, H. J., \& Kim, Y. K. (2009). Indian consumers' purchase intention toward a United States versus local brand. Journal of Business Research, 62(5), 521-527.

Srivastava, R. K., Fahey, L., \& Christensen, H. K. (2001). The Resource-Based View And Marketing: The Role of Market-Based Assets in Gaining Competitive Advantage. Journal of Management, 27(6), 777-802 
Teo, L., Leng, H. and Phua, Y. (2019), "Marketing on Instagram". International Journal of Sports Marketing and Sponsorship, Vol. 20 No. 2, pp. 321-332

Tseng, F.C., Cheng, T.C.E., Li, K., \& Teng, C.I (2016) How Does Media Richness Contribute to Customer Loyalty, Procedia - Social and Behavioural Sciences, 213, pp 88-99

Valentini, C., Romenti, S., Murtareli, G., \& Pizetti, M., (2018) Digital Visual Engagement: Influencing Purchase Intentions On Instagram. Journal of Communication Management, Vol 22, No. 4, pp 362-381

"What is Instagram?" 2019. Instagram. Accessed September 18, 2019 from https://help.instagram.com/424737657584573

Yan Yang, Xiaoming Liu \& Jun Li (2015). How Customer Experience Affects the CustomerBased Brand Equity for Tourism Destinations, Journal of Travel \& Tourism Marketing, 32(1), 97-113. 